\title{
Characterization of Denitrifying Phosphorus Removal Microorganisms in a Novel Two-Sludge Process by Combining Chemical with Microbial Analysis
}

\author{
Haiming Zou, ${ }^{1,2}$ Xiwu Lu, ${ }^{1}$ and Saad Abualhail ${ }^{1,3}$ \\ ${ }^{1}$ School of Energy and Environment, Southeast University, Nanjing, Jiangsu 210096, China \\ ${ }^{2}$ Department of Resource and Environment, Anhui Science and Technology University, Fengyang, Anhui 233100, China \\ ${ }^{3}$ Department of Civil Engineering, College of Engineering, University of Basrah, Basra, Iraq \\ Correspondence should be addressed to Xiwu Lu; xiwulu@seu.edu.cn
}

Received 17 May 2013; Accepted 3 October 2013; Published 8 January 2014

Academic Editor: José Morillo

Copyright ( 2014 Haiming Zou et al. This is an open access article distributed under the Creative Commons Attribution License, which permits unrestricted use, distribution, and reproduction in any medium, provided the original work is properly cited.

\begin{abstract}
The present work focuses on the investigation of denitrifying phosphorus removal organisms (DPB) in a novel two-sludge denitrifying phosphorus removal process by combining chemical with microbial analysis. When the two-sludge process operated stably over one year, good phosphorus $(\mathrm{P})$ release and $\mathrm{P}$ uptake performance of activated sludge samples collected from this process were present in anaerobic and anoxic conditions, respectively, via batch test, showing that the ratio of $\mathrm{P}$ release specific rate to $\mathrm{P}$ uptake specific rate was 1.31. The analysis of energy dispersive spectrometry (EDS) showed that P content of activated sludge samples collected at the end of anoxic phase was $12.3 \%$ of dry weight, further demonstrating the existence of microorganisms responsible for phosphorus removal in this two-sludge process. From polymerase chain reaction-denaturing gradient gel electrophoresis (PCR-DGGE) analysis, the presence of microorganisms mostly belonging to the phyla Firmicutes and Proteobacteria was observed, previously evidenced in the phosphorus removal wastewater treatment process. Fluorescence in situ hybridization (FISH) quantitative analysis showed that Accumulibacter responsible for phosphorus removal was dominant in this two-sludge process, accounting for $69.7 \%$ of all bacteria in activated sludge. These results obtained from chemical and microbial analysis in this study suggested that denitrifying phosphorus removal microorganisms were completely enriched in the two-sludge process proposed here.
\end{abstract}

\section{Introduction}

Phosphorus $(\mathrm{P})$ is one of the nutrients that can cause eutrophication of lakes, inland seas, and other natural waters, which threaten the safety of drinking water systems and ecological risk. Removal of P from wastewater is therefore important for preventing eutrophication. Nowadays, enhanced biological phosphorus removal (EBPR) has been broadly applied in wastewater containing phosphorus $(\mathrm{P})$ treatment because of its lower cost and more environmental friendly technology compared to chemical precipitation or adsorption [1]. Different from chemical or physical treatment methods, EBPR, like other biological wastewater treatment systems, depends on the metabolism of microbial communities to remove $\mathrm{P}$, possibly removing simultaneously organic or inorganic pollutants. Although EBPR system is an economic and environmental friendly technology for meeting the low $\mathrm{P}$ concentration in effluent, this process is difficult to control and is not always stable in the performance of $\mathrm{P}$ removal [2], probably due to a lack of understanding of microbiology in EBPR. So, a better understanding of microbial communities in this system can give an important guidance for stable operation as well as reconstruction [3, 4]. Many molecular techniques used for microbial community analysis have been rapidly developed during the past decade, such as polymerase chain reaction-denaturing gradient gel electrophoresis (PCRDGGE) $[5,6]$ and fluorescence in situ hybridization (FISH) $[7,8]$. Compared with traditional microbial identification technology (culture-dependent and isolation), these methods 
can detect various microorganisms including both cultured bacteria and uncultured bacteria [9].

Although PCR-DGGE can directly analyze the microbial community and diversity of a given system based on $16 \mathrm{~S}$ rDNA fragments without the need to culture or isolate individual species, it is not quantitative [10]. In contrast, FISH can visualize the particular microbial group in a given system with a fluorescently labeled oligonucleotide probe and generally quantify them according to the fluorescence intensities [11]. A combination of PCR-DGGE with FISH technique has been successfully applied to identify the most probable dominant microorganisms and quantify them in a mixture as well as various wastewater treatment processes. Ziembinska et al. [12] characterized the ammonia-oxidizing bacterial community structure in a membrane bioreactor by using PCR-DGGE and FISH, and similar research was reported by Moura et al. [13].

The main objectives of current work are to characterize the denitrifying phosphorus removal bacteria (DPB) in a novel two-sludge denitrifying phosphorus removal process, stably running over one year (detailed later) by using chemi$\mathrm{cal}$ and microbial analysis. The $\mathrm{P}$ release and uptake capacities of DPB under anaerobic and anoxic conditions were conducted via batch tests. Microbial community structure in the anoxic tank within this process was analyzed by PCR-DGGE and the target microorganism was detected and qualified through FISH. Experimental results obtained here would assist in understanding of microbial characteristics in relation to denitrifying $\mathrm{P}$ removal in an EBPR system, in optimization of process parameters and also in stable operation of process.

\section{Materials and Methods}

2.1. Two-Sludge Process Characteristics and Activated Sludge Samples. A lab-scale two-sludge denitrifying phosphorus removal and induced crystallization process (hereafter referred to as two-sludge process; see Figure 1) investigated in this study was established in 2010 and has been stably running over one year. Compared with the conventional wastewater treatment processes, such as sequencing batch reactor $(\mathrm{SBR})$ and anaerobic-anoxic-oxic $\left(\mathrm{A}^{2} \mathrm{O}\right)$ process, the two-sludge process studied here has a great advantage to separate the two parts of activated sludge: nitrification and denitrifying $\mathrm{P}$ removal. This process successfully solves the contradiction of sludge retention time (SRT) between nitrifying bacteria and denitrifying $P$ removal bacteria, which has been applied for a parent (no. 201110431802.4) in China. During the two-sludge process, $\mathrm{P}$ is released anaerobically through the hydrolysis of polyphosphorus accumulated within intracellular bacteria, accompanied by the volatile fatty acids (VFA) stored mostly as poly- $\beta$-hydroxybutyrate (PHB) and the degradation of glycogen. And then, a higher amount of $\mathrm{P}$, in excess of normal metabolic requirements of DPB, is taken up when nitrate is supplied instead of oxygen, which is combined with the growth of biomass and the regeneration of glycogen. Moreover, parts of phosphorus in wastewater can be recovered by means of induced crystallization, which is significantly advantageous to conventional phosphorus removal process, as evidenced
TABLE 1: Components of wastewater used for experiment.

\begin{tabular}{lccc}
\hline $\begin{array}{l}\text { Composition } \\
\text { of feeds }\end{array}$ & Content g/L & $\begin{array}{c}\text { Composition of nutrient } \\
\text { solution }\end{array}$ & $\begin{array}{c}\text { Content } \\
\text { g/L }\end{array}$ \\
\hline $\mathrm{CH}_{3} \mathrm{COONa}$ & 0.45 & $\mathrm{FeCl}_{3} \cdot 6 \mathrm{H}_{2} \mathrm{O}$ & 1.50 \\
$\mathrm{KH}_{2} \mathrm{PO}_{4}$ & 0.09 & $\mathrm{H}_{3} \mathrm{BO}_{3}$ & 0.15 \\
$\left(\mathrm{NH}_{4}\right)_{2} \mathrm{SO}_{4}$ & 0.47 & $\mathrm{CuSO}_{4} \cdot 5 \mathrm{H}_{2} \mathrm{O}$ & 0.03 \\
$\mathrm{CaCl}_{2}$ & 0.02 & $\mathrm{KI}$ & 0.18 \\
$\mathrm{MgSO}_{4} \cdot 7 \mathrm{H}_{2} \mathrm{O}$ & 0.18 & $\mathrm{MnCl}_{2} \cdot 4 \mathrm{H}_{2} \mathrm{O}$ & 0.12 \\
$\begin{array}{l}\text { Nutrient } \\
\text { solution }\end{array}$ & $0.60 \mathrm{~mL}$ & $\mathrm{Na}_{2} \mathrm{MoO}_{4} \cdot 2 \mathrm{H}_{2} \mathrm{O}$ & 0.06 \\
& & $\mathrm{ZnSO}_{4} \cdot 7 \mathrm{H}_{2} \mathrm{O}$ & 0.12 \\
& & $\mathrm{CoCl}_{2} \cdot 6 \mathrm{H}_{2} \mathrm{O}$ & 0.15 \\
& & $\mathrm{EDTA}$ & 10.00 \\
\hline
\end{tabular}

in our previous study [14]. Activated sludge samples for chemical and microbial analyze were taken from the anoxic tank proposed in this study.

2.2. Batch Tests. In order to assess the $\mathrm{P}$ release and uptake capacities of activated sludge from anoxic tank studied here, a batch test was adopted under the anaerobic-anoxic condition. For the batch test, $0.5 \mathrm{~L}$ of activated sludge was taken from anoxic tank and immediately washed twice with the nutrient solution (see Table 1) not containing the basic medium. The treated activated sludge was filled into one $1 \mathrm{~L}$ test device (transformed triangular flask). Before the anaerobic phase, $0.5 \mathrm{~L}$ of synthetic wastewater was added to achieve an initial concentration of $350 \mathrm{mg} \mathrm{COD} / \mathrm{L}, 20 \mathrm{mg} \mathrm{PO}_{4}{ }^{3-}$-P/L. After a $2 \mathrm{~h}$ anaerobic period, nitrogen gas was supplied in the anoxic condition, with the addition of $45 \mathrm{mg} \mathrm{NO}{ }^{-}-\mathrm{N} / \mathrm{L}$ as well. During this process, the $\mathrm{pH}$ was maintained at $7.0 \pm 0.2$, with the addition of $0.5 \mathrm{~mol} / \mathrm{L} \mathrm{HCl}$ or $0.5 \mathrm{~mol} / \mathrm{L} \mathrm{NaOH}$ when above or below this setpoint. The device was operated at room temperature $\left(20 \pm 0.5^{\circ} \mathrm{C}\right)$.

2.3. DNA Extraction, PCR Amplification, and DGGE. In order to analyze the microbial community, sludge sample from anoxic tank proposed here was subjected to DGGE analysis according to the following rules.

DNA Extraction. Total community DNA was extracted from $300 \mathrm{mg}$ of sludge using FastDNA SPIN Kit for soil (MP-Bio, USA) following the manufacturer's recommendations, and the extracted DNA was stored at $-20^{\circ} \mathrm{C}$.

PCR Amplification. Around $10 \mathrm{ng}$ of DNA was used as a template and the variable $\mathrm{V} 3$ region of its $16 \mathrm{~S}$ rDNA was amplified by PCR using universal primers, both $341 \mathrm{~F}\left(5^{\prime}\right.$-CCTACGGGAGGCAGCAG- $\left.3^{\prime}\right)$ and 534R $\left(5^{\prime}\right.$ ATTACCGCGGCTGCTGG- $3^{\prime}$ ), targeted to conserved regions of its $16 \mathrm{~S}$ rRNA genes. The PCR amplification was performed in a PCR thermal cycler dice (Takara, Japan) according to the reported method [15].

DGGE. The Dcode system (Bio-Rad, USA) was used for DGGE following the protocol of analysis as previously 


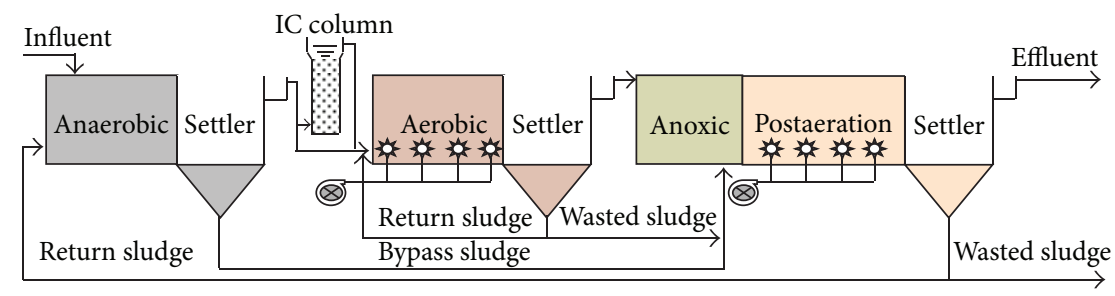

FIGURE 1: A two-sludge denitrifying phosphorus removal and induced crystallization process.

TABLE 2: FISH probes used in this study.

\begin{tabular}{lcccc}
\hline Probe mix & Probe & Sequence $\left(5^{\prime}-3^{\prime}\right)$ & rRNA & Dye $5^{\prime}$ \\
\hline \multirow{3}{*}{ PAOmix } & PAO651 & CCCTCTGCCAAACTCCAG & $16 S$ & Cy3 \\
& PAO462 & CCGTCATCTACWCAGGGTATTAAC & 165 & Cy3 \\
& PAO846 & GTTAGCTACGGCACTAAAAGG & $16 S$ & Cy3 \\
\hline
\end{tabular}

Notes: PAO651, PAO462, and PAO846 were applied together (PAOmix comprising equal amounts of those three probes) to target the Accumulibacter, a known phosphorus removal microorganism.

reported [15]. Individual $16 \mathrm{~S}$ rRNA bands from DGGE gels were excised using sterile tips, eluted in $50 \mathrm{uL}$ of sterile deionized water, and stored overnight at $4^{\circ} \mathrm{C}$. The same PCR process as mentioned above was conducted for DNA reamplification. DNA sequencing analysis was performed by the Sangon Biotech Co., Ltd., Shanghai, China. These sequencing results were compared with the reference sequences in the BLAST program, the National Center for Biotechnology Information (NCBI, http://www.ncbi.nlm.nih.gov/) database.

Phylogenetic tree of $16 \mathrm{~S}$ rDNA excised from DGGE was carried out with MEGA version 5.0 employing 1000 bootstrap resamplings.

2.4. FISH Analysis. In order to investigate the abundance of DPB in activated sludge from the two-sludge process studied here, FISH was performed according to the protocol.

Samples Fixation. Fixed sludge samples with a $4 \%$ paraformaldehyde as mentioned above were centrifuged $(5000 \times \mathrm{g}$ RCF for $5 \mathrm{~min}$ ), washed twice in $0.01 \mathrm{M} \mathrm{PBS}$, and then resuspended in a PBS-ethanol solution $(1: 1, \mathrm{vol} / \mathrm{vol})$, being stored at $-20^{\circ} \mathrm{C}$.

Fixed Samples Dehydration. Before dehydration, the fixed sludge samples were firstly homogenized using a homogenizer for 3 times at $30 \mathrm{~s}$ each time. Homogenized samples were spotted onto slides treated in 3-aminopropyltriethoxysilane (APES): acetone (1:50, vol/vol) and then dried for $30 \mathrm{~min}$ at $40^{\circ} \mathrm{C}$. Dried slides containing sludge samples were dehydrated for $3 \mathrm{~min}$ in $50 \%, 80 \%$, and $100 \%$ (vol/vol) ethanol, allowed to air-dry, and then stored in a desiccator prior to hybridization within FISH experiments.

Hybridization. Hybridization of the treated sludge samples was performed for $2.5 \mathrm{~h}$ at $46^{\circ} \mathrm{C}$ in a $1 \mathrm{uL}$ probe $(50 \mathrm{ng} / \mathrm{uL}$; see Table 2) and a $9 \mathrm{uL}$ hybridization buffer solution ( $\mathrm{pH}$ 7.2) including $0.9 \mathrm{M} \mathrm{NaCl}, 20 \mathrm{mM}$ Tris- $\mathrm{HCl}, 0.01 \%$ sodium dodecyl sulfate (SDS), and 35\% formamide for PAOmix.
Washing Samples. When fluorescent in situ hybridization for sludge samples was completed, a stringent washing step was performed for 4 times at 5 min each time in a washing buffer solution $\left(48^{\circ} \mathrm{C}, \mathrm{pH} 7.2\right)$ including $20 \mathrm{mM}$ Tris- $\mathrm{HCl}$, $5 \mathrm{mM}$ EDTA, $0.01 \% \mathrm{SDS}$, and $50 \mathrm{mM} \mathrm{NaCl}$. And then these slides which attached sludge samples were washed by double distilled water, immediately dried at $30^{\circ} \mathrm{C}$ for $2 \mathrm{~h}$, and then were observed with a fluorescence microscope.

DAPI $\left(4^{\prime}, 6\right.$-diamidino-2-phenylindole) staining was performed for targeting the entire bacteria [16]. FISH images were obtained with the BioImaging Navigator fluorescence microscope (Olympus FSX100, Tokyo, Japan) using a software of Olympus FSX-BSW. Quantification of the PAO community relative to the entire bacterial populations was determined by FISH image analysis with the Image-Pro Plus software (version 6.0, USA), following the methodology reported by Wang et al. [17].

\section{Results and Discussion}

During the operation of the two-sludge process proposed here, the characteristics of feed were as follows: the COD concentration range of $152 \sim 237 \mathrm{mg} / \mathrm{L}, \mathrm{NH}_{4}{ }^{+}-\mathrm{N}$ of $23.4 \sim$ $49.8 \mathrm{mg} / \mathrm{L}$, TN of $31.3 \sim 50.5 \mathrm{mg} / \mathrm{L}$, and TP of $3.92 \sim 7.68 \mathrm{mg} / \mathrm{L}$. Correspondingly, the characteristics of final effluent were COD of $10.3 \sim 16.1 \mathrm{mg} / \mathrm{L}$, TN of $9.0 \sim 14.5 \mathrm{mg} / \mathrm{L}$, and TP of $0.17 \sim$ $0.33 \mathrm{mg} / \mathrm{L}$ throughout the whole running period, meeting the A in first grade of Chinese sewage effluent discharge standard (GB 18918-2002), as shown in our previous studies [14].

3.1. Performance of Phosphorus Release and Uptake. In order to investigate in more detail the capacities of $\mathrm{P}$ release and uptake in anaerobic and anoxic phase, respectively, a batch test was adopted to calculate the specific $P$ release and uptake according to the mean, as described in Section 2.2. Based on the characteristics of phosphorus removal microorganisms, moreover, the $\mathrm{P}$ content of activated sludge in both anaerobic and anoxic conditions was investigated by using energy 


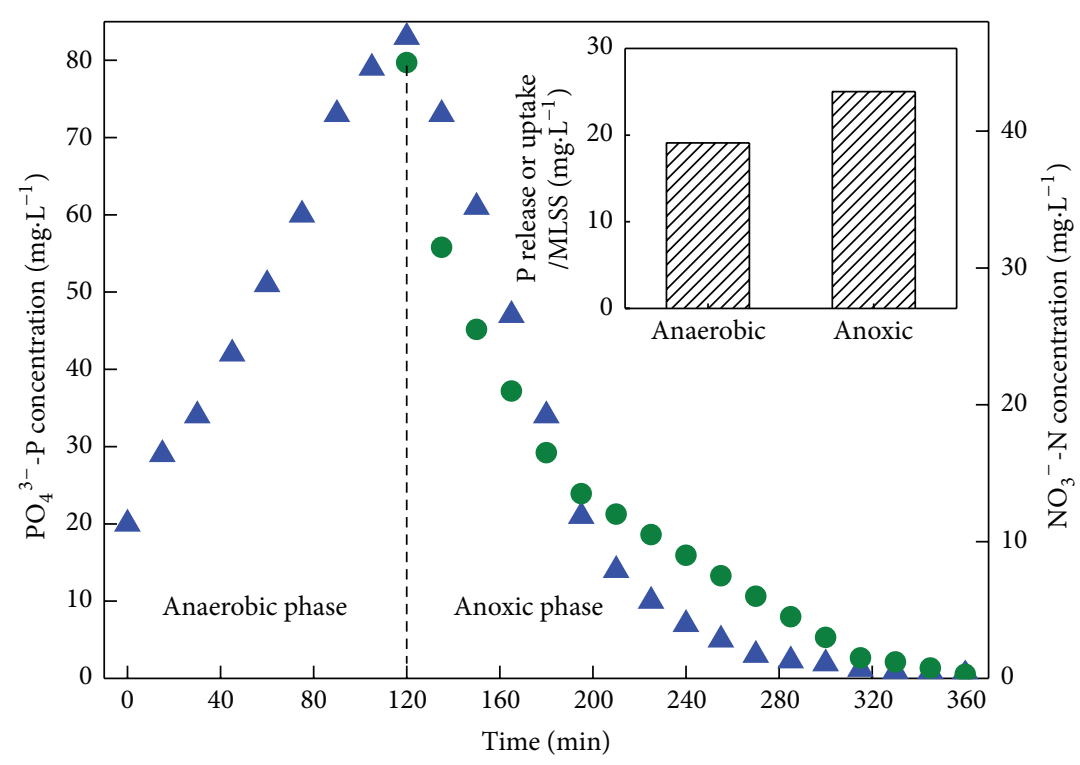

$$
\begin{gathered}
\triangle \mathrm{PO}_{4}{ }^{3-}-\mathrm{P} \\
\mathrm{NO}_{3}{ }^{-}-\mathrm{N}
\end{gathered}
$$

FIGURE 2: Variation of $\mathrm{PO}_{4}{ }^{3-}-\mathrm{P}$ and $\mathrm{NO}_{3}{ }^{-}-\mathrm{N}$ concentrations in anaerobic and anoxic phase and $\mathrm{P}$ release and uptake per MLSS throughout the whole batch test.

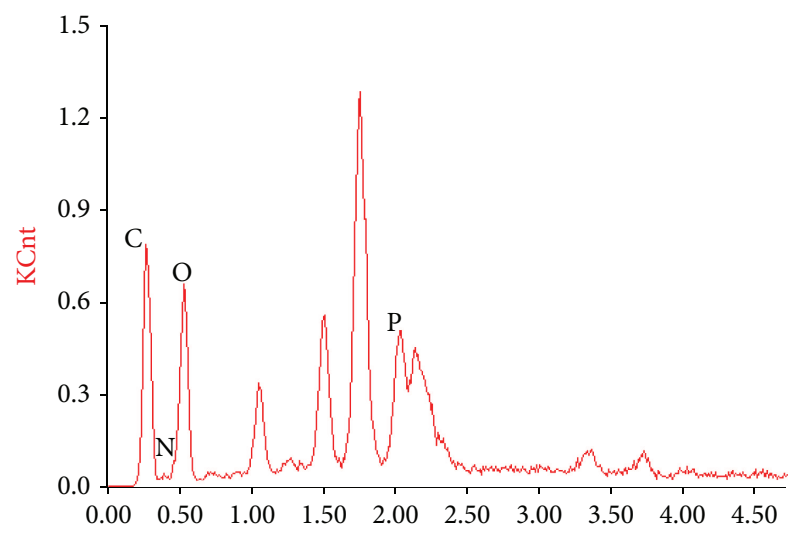

(a) Anaerobic sludge

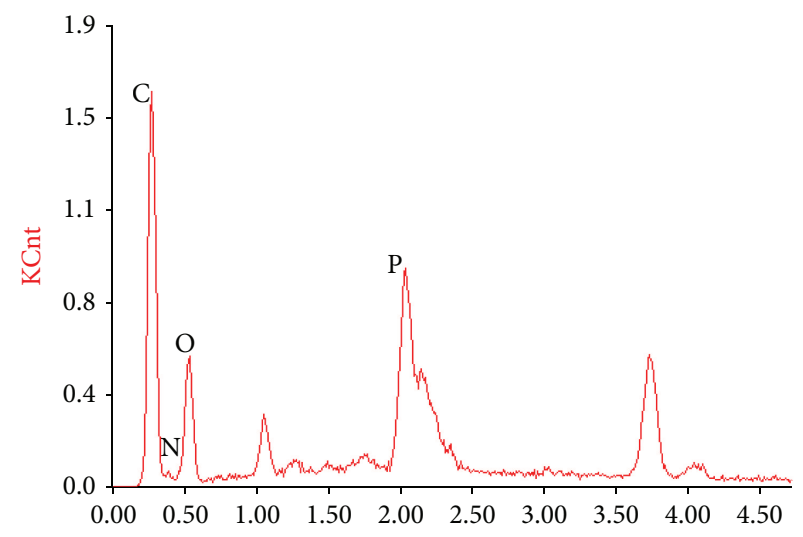

(b) Anoxic sludge

FIGURE 3: Analytical X-ray spectrum of anaerobic sludge and anoxic sludge in two-sludge DPB process, where the spectrum was given with energies of these $\mathrm{X}$-rays $(\mathrm{KeV})$ as abscissa and specific counts of each specific energy as vertical coordinates (KCnt).

dispersive spectrometry (EDS), where, to the best of our knowledge, EDS was the first to be applied in exploring the elements content of activated sludge.

Figure 2 shows variations of $\mathrm{PO}_{4}{ }^{3-}-\mathrm{P}$ and $\mathrm{NO}_{3}{ }^{-}-\mathrm{N}$ concentration in the device as well as its specific $\mathrm{P}$ release and uptake during the whole batch test. A good performance of $\mathrm{P}$ release and uptake was observed in anaerobic and anoxic phase when the initial $\mathrm{PO}_{4}{ }^{3-}-\mathrm{P}$ concentration was $20 \mathrm{mg} / \mathrm{L}$ in the influent. At the anaerobic phase, a $\mathrm{P}$ release rate of $19.09 \mathrm{mg} \mathrm{P} / \mathrm{g}$ MLSS was obtained through the hydrolysis of polyphosphate. After anaerobic phosphorus release, the sludge exhibited rapidly anoxic $\mathrm{P}$ uptake performance with the rate of $25.01 \mathrm{mg} \mathrm{P} / \mathrm{g}$ MLSS. The ratio between anaerobic
$\mathrm{P}$ release and anoxic $\mathrm{P}$ uptake was 1.31, indicating that DPB responsible for $\mathrm{P}$ removal has been greatly enriched in the two-sludge process and the sludge from anoxic tank presented a good P removal capacity. Moreover, a good removal performance of $\mathrm{NO}_{3}{ }^{-}-\mathrm{N}$ was found in anoxic phase, which also demonstrated that simultaneous denitrifying nitrogen and phosphorus removal occurred in this twosludge system.

There was a significant difference in the $\mathrm{P}$ content of activated sludge between anaerobic and anoxic conditions in the two-sludge process proposed here (see Figure 3). The excited atoms counts of $\mathrm{P}$ element in the anaerobic sludge were $0.55 \mathrm{k}$, while they were $1.18 \mathrm{k}$ in the anoxic sludge, suggesting that 
TABLE 3: NCBI BLAST search results of sequences from DGGE bands.

\begin{tabular}{lcccc}
\hline Band & The most related sequence & Similarity \% & Accession number & Phylogenetic affiliation \\
\hline 1 & Roseospira & 91 & NR_042530.1 & $\alpha$-Proteobacteria \\
2 & Azovibrio & 96 & NR_028678.1 & $\beta$-Proteobacteria \\
3 & Dechloromonas & 98 & NR_074748.1 & $\beta$-Proteobacteria \\
4 & Clostridium & 100 & NR_026336.1 & Firmicutes \\
5 & Geobacter & 89 & NR_074979.1 & $\delta$-Proteobacteria \\
\hline
\end{tabular}

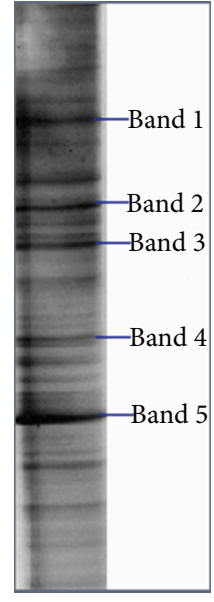

FIGURE 4: DGGE fingerprint of $16 \mathrm{~S}$ rDNA fragments of activated sludge collected from anoxic tank in the two-sludge process proposed here.

the difference of $\mathrm{P}$ content in sludge between anaerobic phase and anoxic phase should be due to the different performances of DPB in different conditions, including that $\mathrm{P}$ was released anaerobically and taken up anoxically. The $P$ content of excess sludge in this study, namely, anoxic sludge, was $12.3 \%$ of dry weight significantly higher than that in traditional biological phosphorus removal process (3\%) [18], which agrees well with the results of chemical analysis, further demonstrating the existence of phosphorus removal microorganisms in this two-sludge process studied here.

3.2. PCR-DGGE Analysis of Activated Sludge Sample. The microbial community composition of activated sludge sample from the anoxic tank in the two-sludge process proposed in this study was investigated through PCR-DGGE analysis and phylogenetic affiliation based on the PCR-amplified genes coding for $16 \mathrm{~S}$ rDNA was also analyzed here. The result of the DGGE separation is shown in Figure 4. DNA bands marked on the fingerprints, numbered Band 1, Band 2, Band 3, Band 4 and Band 5, were excised from the gel and their respective fragments were cloned and then sequenced. Blast sequence results are shown in Table 3 and further phylogenetic analysis is presented in Figure 5.

From Figure 4, there existed many visible or obscure bands indicating complexity and diversity of microbial ecosystems in the activated sludge samples investigated here. Five sequenced bands were similar to microorganisms previously found in activated sludge samples, as shown in Table 3.
It was found that bands from 1 to 5 corresponded to related sequences of five different microbial species, where Band 4 had the highest identity (100\%) with its related sequence (Clostridium sp. belonging to the Clostridia subclass of phylum Firmicutes) compared with four other bands, which were generally consistent with the results reported by others $[19,20]$, giving that some of the organisms in Firmicutes are capable of accumulation of PHB into the cells and are involved in the phosphorus removal process. However, Band 2 and Band 3 were found to belong to the beta subclass of Proteobacteria and Band 1 and Band 5 belong to the alpha and delta subclass of Proteobacteria, respectively, as shown in Figure 5 and Table 3. In many literatures, polyphosphate accumulating organisms, namely, Accumulibacter, have been demonstrated to belong mostly to Proteobacteria [21, 22], mostly in which Rhodocyclus sp. is known to be an important group responsible for phosphorus removal from wastewater [23-25], related to Band 3 in this study.

3.3. In Situ Hybridization for DPB. Although, based on the results of PCR-DGGE and DNA sequencing, it was found that Accumulibacter belonging to the phyla Firmicutes and Proteobacteria was present in the anoxic tank proposed in this study, as shown in Figure 5 and Table 3, DGGE fingerprints obtained from gel did not provide any information on the extent of its predominance in the microbial community [26]. For this, FISH analysis was adopted to monitor the Accumulibacter responsible for phosphorus removal in activated sludge samples studied here, enabling the identification and detection of the specific strains in the microbial community via in situ hybridization with $16 \mathrm{~S}$ rRNA-targeted oligonucleotide probes.

FISH analysis showed that Accumulibacter occupies a considerable proportion of the activated sludge samples from anoxic tank proposed here (see Figure 6), presenting $69.7 \%$ of all bacteria by analyzing the fluorescence intensity involved in image, suggesting that Accumulibacter may play a major role in this process studied here. Moreover, Accumulibacter in situ hybridization with PAOmix probes (pink) formed clusters. Similarly, these results were also found in other EBPR systems [24,27], suggesting that Accumulibacter can be considerably enriched in most phosphorus removal processes when providing advantageous conditions.

\section{Conclusions}

The results of this study, through chemical analysis and microbial analysis, show that denitrifying phosphorus 


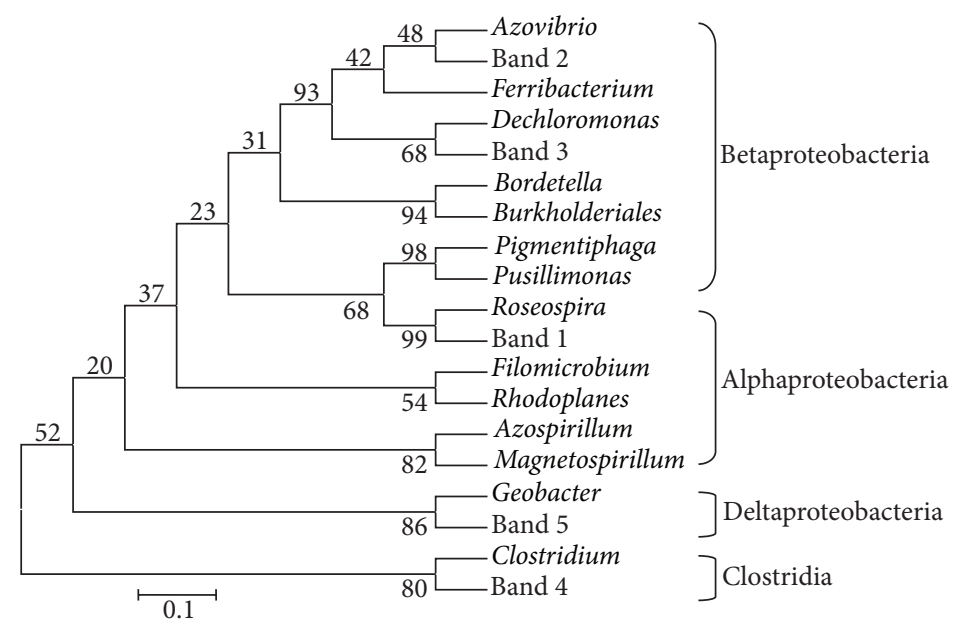

FIGURE 5: Evolutionary tree, carried out in the software of MEGA version 5.1, of $16 \mathrm{~S}$ rDNA excised from DGGE showing the phylogenetic affiliations between strains obtained in activated sludge studied here and their closest relatives derived from GenBank.

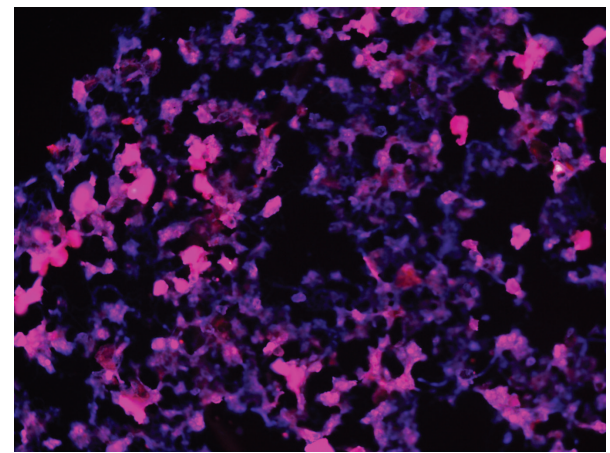

FIGURE 6: FISH image (×50) of Accumulibacter for oligonucleotide probes in the activated sludge samples from anoxic tank; Accumulibacter labeled with $\mathrm{Cy} 3$ is shown in pink combining red with blue, and all other bacteria are shown in blue generated by DAPI staining.

removal organisms (DPB) have been greatly accumulated in the novel two-sludge denitrifying phosphorus removal process over one year of stable operation. It was found that good performance of $\mathrm{P}$ release in anaerobic and $\mathrm{P}$ uptake in anoxic was present via batch test and their specific rates were $19.09 \mathrm{mg} \mathrm{P} / \mathrm{g}$ MLSS and $25.01 \mathrm{mg} \mathrm{P} / \mathrm{g}$ MLSS, respectively, implying the efficient phosphorus removal during denitrification. The $\mathrm{P}$ content of activated sludge in anoxic significantly higher than in anaerobic analyzed by using energy dispersive spectrometry (EDS) also demonstrated the existence of microbes responsible for phosphorus removal in this two-sludge process.

DGGE of PCR-amplified 16S rDNA fragments showed the complexity and diversity in microbial community and the determination of phylogenetic affiliation demonstrated that $\mathrm{DPB}$ enriched in this two-sludge process mostly belong to phyla Firmicutes and Proteobacteria. FISH analysis indicated that Accumulibacter responsible for phosphorus removal occupied a considerable proportion in the activated sludge from anoxic tank, accounting for $69.7 \%$ of all bacteria in sludge samples. Based on the chemical and microbial analysis performed here, the novel two-sludge denitrifying phosphorus removal process may be effective in treatment of wastewater containing carbon, nitrogen, and phosphorus, especially for low $\mathrm{C} / \mathrm{N}$ ratio wastewater.

\section{Conflict of Interests}

The authors declare that there is no conflict of interests regarding the publication of this paper.

\section{Acknowledgments}

The authors wish to thank M. M. SU for assistance with activated sludge treatment and Dr. Wang for enlightening discussion. This research is supported by Grant 2012ZX07101005 from National Key Technology in Water Pollution Control and Treatment in 12th Five-Year Plan of China and Grant 51078074 from National Natural Science Foundation of China.

\section{References}

[1] I. Zafiriadis, A. G. Kapagiannidis, and A. Aivasidis, "Monitoring of microbial storage products and the efficiency of an activated sludge plant performing anoxic phosphorus removal under different operational conditions," Desalination and Water Treatment, vol. 23, no. 1-3, pp. 73-79, 2010.

[2] T. Zeng, D. Wang, X. Li et al., "Comparison between acetate and propionate as carbon sources for phosphorus removal in the aerobic/extended-idle regime," Biochemical Engineering Journal, vol. 70, pp. 151-157, 2013.

[3] K. M. DeAngelis, C. H. Wu, H. R. Beller et al., "PCR amplification-independent methods for detection of microbial communities by the high-density microarray PhyloChip," Applied and Environmental Microbiology, vol. 77, no. 18, pp. 6313-6322, 2011. 
[4] M. Hu, X. Wang, X. Wen, and Y. Xia, "Microbial community structures in different wastewater treatment plants as revealed by 454-pyrosequencing analysis," Bioresource Technology, vol. 117, pp. 72-79, 2012.

[5] L. Wittebolle, W. Verstraete, and N. Boon, “The inoculum effect on the ammonia-oxidizing bacterial communities in parallel sequential batch reactors," Water Research, vol. 43, no. 17, pp. 4149-4158, 2009.

[6] W. Kim, S. Lee, S. G. Shin, C. Lee, K. Hwang, and S. Hwang, "Methanogenic community shift in anaerobic batch digesters treating swine wastewater," Water Research, vol. 44, no. 17, pp. 4900-4907, 2010.

[7] A. S. Çiĝgin, D. Orhon, S. Rossetti, and M. Majone, "Short-term and long-term effects on carbon storage of pulse feeding on acclimated or unacclimated activated sludge," Water Research, vol. 45, no. 10, pp. 3119-3128, 2011.

[8] R. Delatolla, N. Tufenkji, Y. Comeau, A. Gadbois, D. Lamarre, and D. Berk, "Effects of long exposure to low temperatures on nitrifying biofilm and biomass in wastewater treatment," Water Environment Research, vol. 84, pp. 328-338, 2012.

[9] A. Muthaiyan and S. C. Ricke, "Current perspectives on detection of microbial contamination in bioethanol fermentors," Bioresource Technology, vol. 101, no. 13, pp. 5033-5042, 2010.

[10] T. Suematsu, S. Yamashita, H. Hemmi et al., "Quantitative analyses of the behavior of exogenously added bacteria during an acidulocomposting process," Journal of Bioscience and Bioengineering, vol. 114, no. 1, pp. 70-72, 2012.

[11] A. F. Silva, G. Carvalho, A. Oehmen et al., "Microbial population analysis of nutrient removal-related organisms in membrane bioreactors," Applied Microbiology and Biotechnology, vol. 93, no. 5, pp. 2171-2180, 2012.

[12] A. Ziembinska, S. Ciesielski, A. Gnida, S. Zabczynki, J. Surmacz-Gorska, and K. Miksch, "Comparison of ammoniaoxidizing bacterial community structure in membrane-assisted bioreactors using PCR-DGGE and FISH," Journal of Microbiology and Biotechnology, vol. 22, pp. 1035-1043, 2012.

[13] A. Moura, M. Tacão, I. Henriques, J. Dias, P. Ferreira, and A. Correia, "Characterization of bacterial diversity in two aerated lagoons of a wastewater treatment plant using PCR-DGGE analysis," Microbiological Research, vol. 164, no. 5, pp. 560-569, 2009.

[14] J. Shi, X. Lu, R. Yu, and W. Zhu, "Nutrient removal and phosphorus recovery performances of a novel 13 anaerobicanoxic/nitrifying/induced crystallization process," Bioresource Technology, vol. 121, pp. 183-189, 2012.

[15] X. Li, F. Xu, H. Liu, B. Liang, Y. Xu, and L. Jin, "Application of polymerase chain reaction (PCR)-based denaturing gradient gel electrophoresis for analysis of microbiota on the tongue dorsa of subjects with halitosis," African Journal of Microbiology Research, vol. 6, pp. 5789-5795, 2012.

[16] J. L. Nielsen, H. Nguyen, R. L. Meyer, and P. H. Nielsen, "Identification of glucose-fermenting bacteria in a full-scale enhanced biological phosphorus removal plant by stable isotope probing," Microbiology, vol. 158, pp. 1818-1825, 2012.

[17] X. H. Wang, M. H. Diao, Y. Yang, Y. J. Shi, M. M. Gao, and S. G. Wang, "Enhanced aerobic nitrifying granulation by static magnetic field," Bioresource Technology, vol. 110, pp. 105-110, 2012.

[18] P. H. Nielsen, A. M. Saunders, A. A. Hansen, P. Larsen, and J. L. Nielsen, "Microbial communities involved in enhanced biological phosphorus removal from wastewater-a model system in environmental biotechnology," Current Opinion in Biotechnology, vol. 23, no. 3, pp. 452-459, 2011.

[19] M. Venkateswar Reddy and S. Venkata Mohan, "Effect of substrate load and nutrients concentration on the polyhydroxyalkanoates (PHA) production using mixed consortia through wastewater treatment," Bioresource Technology, vol. 114, pp. 573582, 2012.

[20] S. G. Dastager, C. K. Deepa, and A. Pandey, "Growth enhancement of black pepper (Piper nigrum) by a newly isolated Bacillus tequilensis NII-0943," Biologia, vol. 66, no. 5, pp. 801-806, 2011.

[21] A. Kawakoshi, H. Nakazawa, J. Fukada et al., "Deciphering the Genome of polyphosphate accumulating actinobacterium Microlunatus phosphovorus," DNA Research, vol. 19, no. 5, pp. 383-383, 2012.

[22] H. Lu, A. Oehmen, B. Virdis, J. Keller, and Z. Yuan, "Obtaining highly enriched cultures of Candidatus Accumulibacter phosphates through alternating carbon sources," Water Research, vol. 40, no. 20, pp. 3838-3848, 2006.

[23] Y. H. Ge, L. Zhao, R. C. Zhang, and Y. J. Liu, “Optimization and application of fluorescence in situ hybridization assay for detecting polyphosphate-accumulating microorganisms," Advanced Materials Research, vol. 183-185, pp. 1369-1373, 2011.

[24] B. Acevedo, A. Oehmen, G. Carvalho, A. Seco, L. Borrás, and R. Barat, "Metabolic shift of polyphosphate-accumulating organisms with different levels of polyphosphate storage," Water Research, vol. 46, no. 6, pp. 1889-1900, 2012.

[25] M. K. Winkler, R. Kleerebezem, W. Khunjar, B. de Bruin, and M. van Loosdrecht, "Evaluating the solid retention time of bacteria in flocculent and granular sludge," Water Research, vol. 46, pp. 4973-4980, 2012.

[26] S. Wang and C. K. Gunsch, "Effects of selected pharmaceutically active compounds on treatment performance in sequencing batch reactors mimicking wastewater treatment plants operations," Water Research, vol. 45, no. 11, pp. 3398-3406, 2011.

[27] A. T. Mielczarek, H. T. T. Nguyen, J. L. Nielsen, and P. H. Nielsen, "Population dynamics of bacteria involved in enhanced biological phosphorus removal in Danish wastewater treatment plants," Water Research, vol. 47, pp. 1529-1544, 2012. 

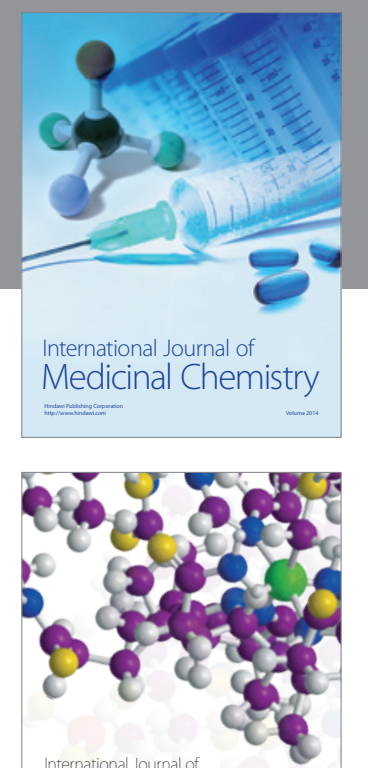

\section{Carbohydrate} Chemistry

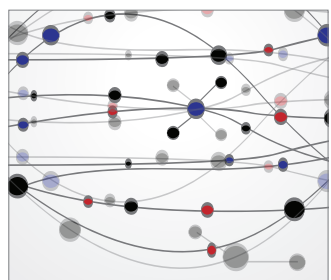

The Scientific World Journal
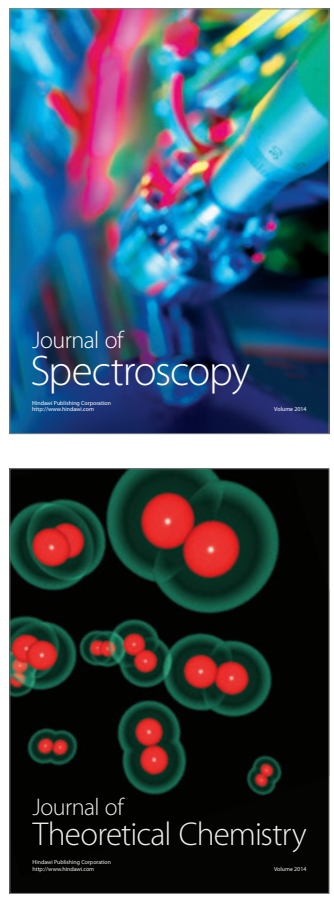
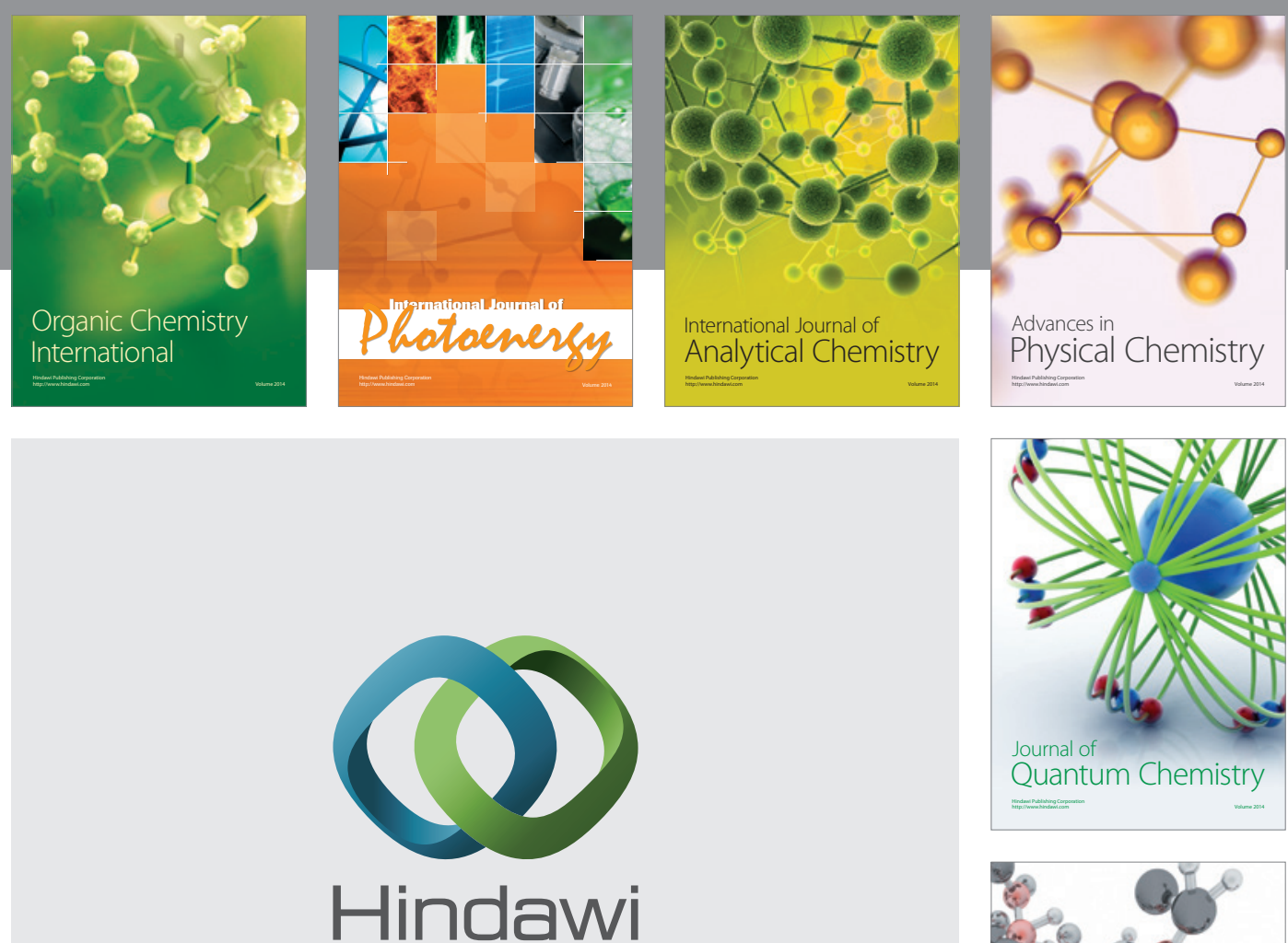

Submit your manuscripts at

http://www.hindawi.com

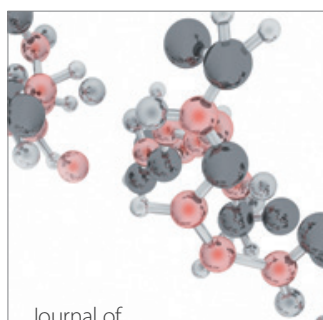

Analytical Methods

in Chemistry

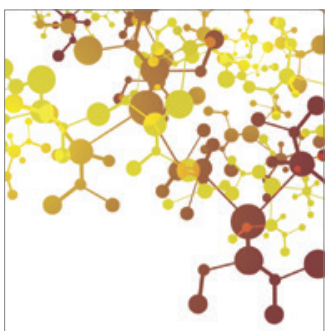

Journal of

Applied Chemistry

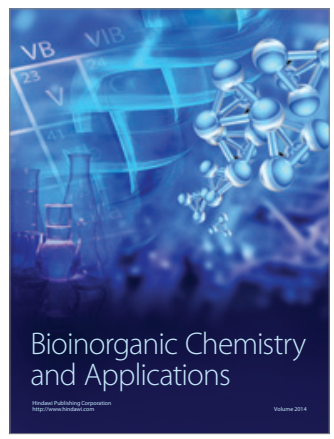

Inorganic Chemistry
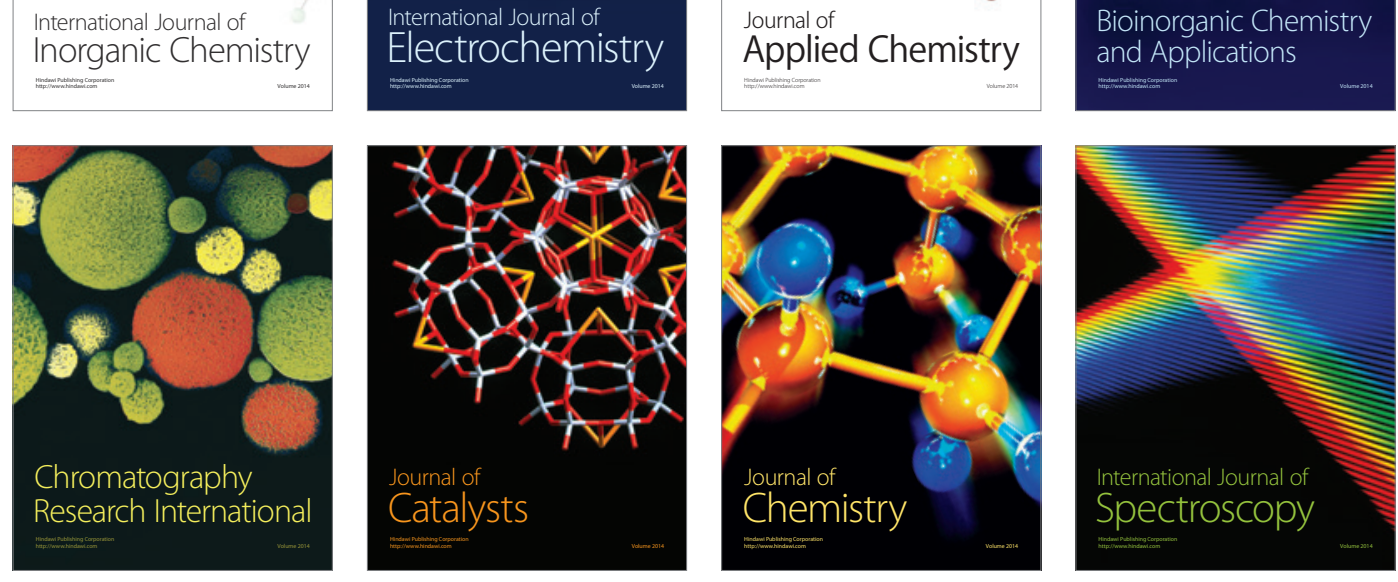